\title{
Zinc-Triggered Hierarchical Self-Assembly of Fibrous Helix-Loop-Helix Peptide Superstructures for Controlled Encapsulation and Release
}

\author{
Christopher Aronsson, Robert Selegård and Daniel Aili
}

Journal Article

\section{Tweet}

N.B.: When citing this work, cite the original article.

Original Publication:

Christopher Aronsson, Robert Selegård and Daniel Aili, Zinc-Triggered Hierarchical SelfAssembly of Fibrous Helix-Loop-Helix Peptide Superstructures for Controlled Encapsulation and Release, Macromolecules, 2016. 49(18), pp.6997-7003.

http://dx.doi.org/10.1021/acs.macromol.6b01724

Copyright: American Chemical Society

http://pubs.acs.org/

Postprint available at: Linköping University Electronic Press

http://urn.kb.se/resolve?urn=urn:nbn:se:liu:diva-132215

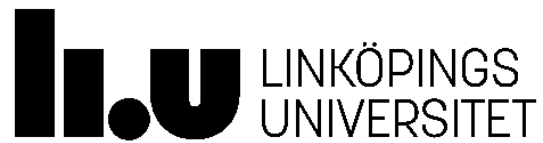




\title{
Zinc-triggered Hierarchical Self-Assembly of Fibrous Helix-Loop-
}

\section{Helix Peptide Superstructures for Controlled Encapsulation and}

\section{Release}

Christopher Aronsson ${ }^{\dagger}$, Robert Selegård ${ }^{\dagger}$, and Daniel Aili*

Division of Molecular Physics, Department of Physics, Chemistry and Biology, Linköping University, 58183 Linköping, Sweden.

\begin{abstract}
We demonstrate a novel route for hierarchical self-assembly of sub-micron sized peptide superstructures that respond to subtle changes in $\mathrm{Zn}^{2+}$ concentration. The self-assembly process is triggered by a specific foldingdependent coordination of $\mathrm{Zn}^{2+}$ by a de novo designed non-linear helix-loop-helix peptide, resulting in a propagating fiber formation and formation of spherical superstructures. The superstructures further forms larger assemblies that can be completely disassembled upon removal of $\mathrm{Zn}^{2+}$ or degradation of the non-linear peptide. This flexible and reversible assembly strategy of the superstructures enable facile encapsulation of nanoparticles and drugs that can be released by means of different stimuli.
\end{abstract}

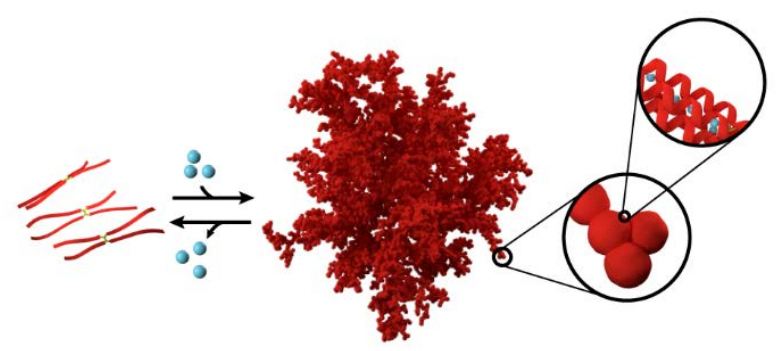

(for Table of Contents only) 


\section{Introduction}

Peptide-directed self-assembly is a versatile tool for fabrication of structurally well-defined functional materials, such as nanoparticles, ${ }^{1-3}$ fibers, ${ }^{4-7}$ and hydrogels. ${ }^{8-11}$ The extraordinary chemical flexibility of peptides, combined with the well-established design rules for obtaining defined structural motifs, such as $\alpha$-helical coiled coils, ${ }^{12}$ and the possibilities to include bioactive amino acid sequences, such as RGD and IKVAV for cell adhesion, ${ }^{13}$ enables several possibilities to make self-assembling and stimuli-responsive peptide-based materials. The peptide selfassembly process can be triggered and controlled by subtle changes in e.g. $\mathrm{pH},{ }^{14-16}$ temperature, ${ }^{17,18}$ metal ion coordination, ${ }^{19-21}$ and by specific interactions with complementary peptides or other biomolecules. ${ }^{22-24}$ The numerous possibilities to modulate the assembly process have enabled development of a wide range of peptidebased materials for applications in biosensing,,$^{25,26}$ drug delivery, ${ }^{27,28}$ and tissue engineering. ${ }^{29}, 30$

Metal cations are attractive modulators of peptide-directed self-assembly since peptides can coordinate certain cations with high specificity and affinity. ${ }^{31}$ Yet, the interactions are reversible and the bound metal ions can be removed by competing ligands showing higher metal ion affinities, including common chelating agents such as ethylenediamine-tetraacetic acid (EDTA), citrate and phytic acid, ${ }^{32}$ and serum components such as albumin. $\mathrm{Zn}^{2+}$ is one of the most frequently found metal cation in metalloproteins, for instance found in DNA binding zinc finger motifs, ${ }^{33}$ and as well in numerous enzymes including carbonic anhydrases, metalloproteinases, and carboxypeptidases. ${ }^{34}$ In addition to the catalytic role of $\mathrm{Zn}^{2+}$ in metalloenzymes, its prevalence in proteins stem from its extraordinary ability to coordinate to many different amino acids (e.g. glutamic acid, aspartic acid and histidine) due to its flexible coordination geometries. ${ }^{35}$ Numerous other biomolecules and drugs, such as vitamin $\mathrm{B}_{9}$, acetylsalicylic acid and nucleotides, do also interact with $\mathrm{Zn}^{2+} \cdot 36-38$ The possibility to exploit $\mathrm{Zn}^{2+}$ - peptide interactions is thus an attractive route to both control peptide folding and to tailor the properties of responsive peptide-based materials and nanostructures, and for fabrication of various supramolecular hybrid materials.

In this paper we investigate a novel strategy to hierarchically self-assemble peptide superstructures using $\mathrm{Zn}^{2+}$ triggered folding of a de novo designed helix-loop-helix polypeptide (Figure 1a). In the presence of $\mathrm{Zn}^{2+}$ the peptides fold and self-assemble into spherical superstructures that gradually grows into larger fibrous assemblies. The process depends on the folding of the polypeptides and is fully reversible as complete disassembly occurs 
upon removal of the $\mathrm{Zn}^{2+}$. Since numerous compounds, including drugs and functionalized nanoparticles, also can coordinate $\mathrm{Zn}^{2+}$ they can be encapsulated in the superstructures with high efficiency if present during the assembly process. The possibility to trigger the disassembly of the peptide superstructures offers means to control the release rate of encapsulated species. The specific folding-dependent interactions modulated by peptide coordination of $\mathrm{Zn}^{2+}$ thus offers routes for fabrication of dynamic and stimuli-responsive soft nanostructured materials with defined and tunable properties and a novel strategy for encapsulation and release of drugs.
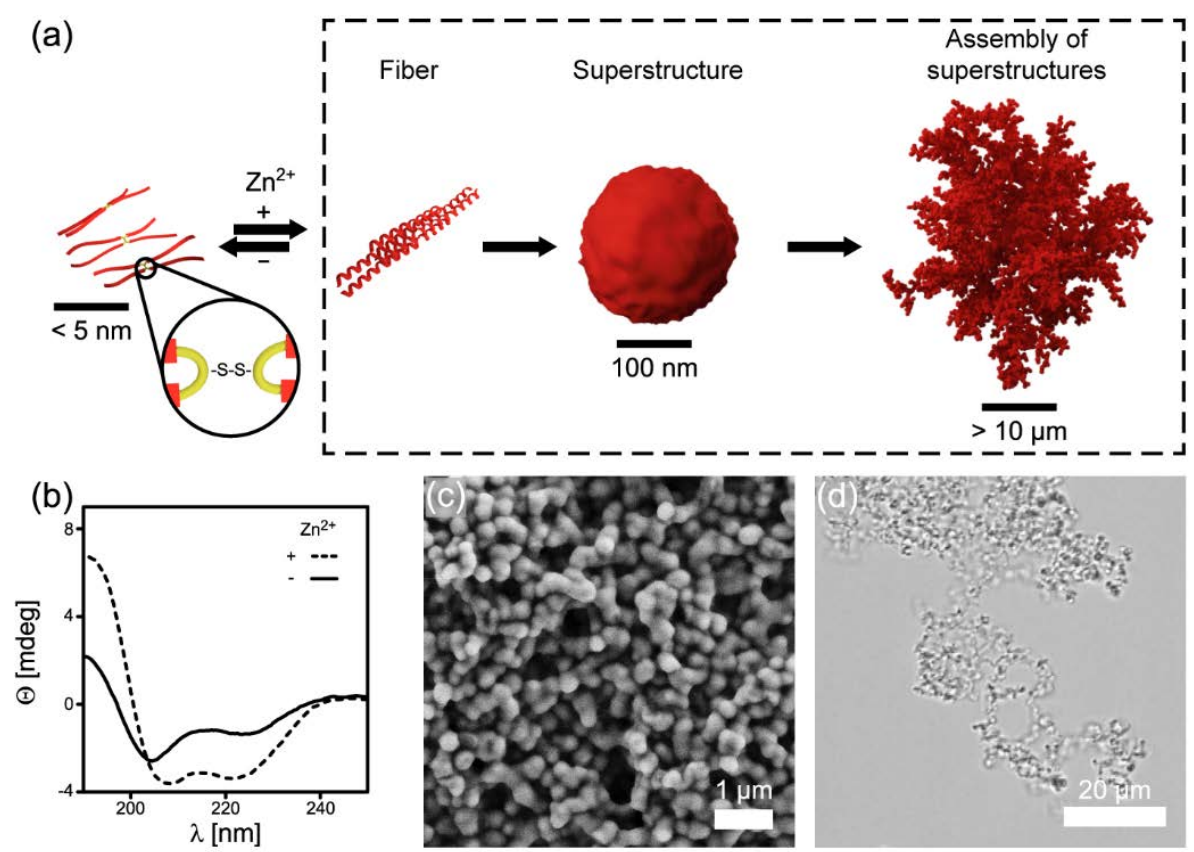

Figure 1 a) Schematic representation of the self-assembly process. $\mathrm{Zn}^{2+}$ triggers the process and over time large assemblies of spherical superstructures will form. b) CD spectra of $\mathrm{JR}_{2} \mathrm{EC}_{2}$ with and without $1 \mathrm{mM} \mathrm{Zn}^{2+}$. c) SEM micrograph and. d) Photomicrograph of superstructures.

\section{Experimental details}

General. Amino acids and chemicals for peptide synthesis were acquired from Iris Biotech GmbH (Germany). The oligothiophene p-FTAA ${ }^{39}$ were kindly provided by the group of Peter Nilsson at Linköping University. All other chemicals were acquired from Sigma Aldrich (Sweden). All experiments were conducted in Bis-Tris buffer (30 mM, pH 7) at room temperature if nothing else is stated.

Synthesis and purification of peptides. JR2EC, JR2E and D-Ala-JR2EC (peptide identity and sequences in Supporting Information) were synthesized using Fmoc-strategy and sequentially purified as described 
previously. ${ }^{26}$ Linking two peptides via a disulfide bridge was carried out by dissolving peptides $(2 \mathrm{mg} / \mathrm{ml})$ in ammonium hydrogen carbonate buffer $(10 \mathrm{mM}, \mathrm{pH}$ 8.5), and subsequent incubation for 72 hours at room temperature on an orbital-shaker. Formation of the disulfide bridge was confirmed by an Ellman's test of free thiols. ${ }^{40}$ The linked peptides were then diluted with two-fold of double-filtered distilled water, rotary evaporated twice and sequentially lyophilized to a dry powder.

Gold nanoparticle functionalization. JR2EC functionalized AuNPs (40 $\mathrm{nm}$ in radius) were synthesized as described previously. ${ }^{26}$ AuNPs $~ 70 \mathrm{nM}$ (BBI Solutions, UK) were incubated with $10 \mu \mathrm{M}$ JR2EC (10 mM sodium citrate, $\mathrm{pH}$ 6) at $4{ }^{\circ} \mathrm{C}$ overnight. After incubation the particles were repeatedly centrifuged (12,000 × g, $\left.30 \mathrm{~min}\right)$ and the buffer subsequently exchanged with Bis-Tris buffer (30 mM, $\mathrm{pH}$ 7) until the concentration of unbound JR2EC was below 5 pM. The concentration of JR2EC-AuNP was calculated using an extinction coefficient of $1.03 \times 10^{10} \mathrm{M}^{-1} \mathrm{~cm}^{-1}{ }^{41}$

Folding of polypeptides. The secondary structures of JR2EC 2 and D-Ala-JR2EC $\mathrm{E}_{2}$ were investigated by circular dichroism (CD) spectroscopy with a Chirascan ${ }^{\mathrm{TM}}$ spectropolarimeter from Applied Photophysics (UK). CD spectra were acquired between 190 and $250 \mathrm{~nm}$ at $20^{\circ} \mathrm{C}$ with a resolution of $0.5 \mathrm{~nm}$. Each sample was incubated in BisTris buffer (30 mM, pH 7) with desired $\mathrm{Zn}^{2+}$ concentration $(0-2 \mathrm{mM})$ at room temperature for 30 min prior measurement. The ratio of the ellipticities at 222 and $208 \mathrm{~nm}$ was calculated to compare the difference in helicity of JR2EC 2 and D-Ala-JR2EC ${ }_{2}{ }^{42}$

Formation of superstructures. If nothing else is stated, JR2EC $2(50 \mu \mathrm{M})$ was incubated with $\mathrm{Zn}^{2+}(4 \mathrm{mM})$ in Bis-Tris buffer (30 mM, pH 7) for 24 hours. In encapsulation studies with Rhodamine-B and p-FTAA, $10 \mu \mathrm{M}$ of the desired compound was added prior $\mathrm{Zn}^{2+}$ as well. In encapsulation studies with JR2EC-AuNPs, $0.40 \mathrm{nM}$ was added prior $\mathrm{Zn}^{2+}$. Formed superstructures with encapsulated compounds were thoroughly washed by three rounds of centrifugation $(2,000 \times \mathrm{g}, 30 \mathrm{~s})$ to remove non-encapsulated compounds. The supernatant was removed in each round of centrifugation and the formed pellet was resuspended in Bis-Tris buffer with $4 \mathrm{mM} \mathrm{Zn}^{2+}$.

Imaging of assemblies. Optical and epi-fluorescence microscopy: Optical micrographs were acquired with an Eclipse TI microscope from Nikon (Japan). Epi-fluorescence micrographs of samples containing Rhodamine-B and p-FTAA were acquired using fluorescence filter cubes (Rhodamine-B: ex: 528 - $553 \mathrm{~nm}$, em: 590 - $650 \mathrm{~nm}$; p-FTAA: ex: 400 - 440 nm, em: 470- $\infty \mathrm{nm})$.

Scanning electron microscopy: Scanning electron micrographs were acquired with a LEO 1550 Gemini from Zeiss (Germany) operating at $3 \mathrm{kV}$. Samples were centrifuged $(2,000 \times \mathrm{g}, 30 \mathrm{~s})$ and the formed pellet was put onto 
conductive carbon tabs. The samples were air-dried overnight at room temperature and sputter coated with a thin layer of tungsten prior measurement.

Transmission electron microscopy: Transmission electron micrographs were acquired with a Tecnai G2 F20 UltraTwin microscope from Fei (USA) operating at $200 \mathrm{kV}$. Preformed samples were incubated on carbon coated TEM grids for 10 min and excess liquid was sequentially wicked away using filter paper. Samples were air-dried overnight prior measurement.

Photographs were acquired with a Nikon D7000 digital camera.

Turbidity measurements. Turbidity measurements were performed by monitoring the absorbance at $340 \mathrm{~nm}$ with a FLUOstar galaxy microplate reader from BMG Labtech (Germany).

Dynamic light scattering. Dynamic light scattering experiments were performed with an ALV/DLS/SLS-5022F system from ALV-GmbH (Germany). The He-Ne laser was operated at $632.8 \mathrm{~nm}$ and the scattered light was detected perpendicular to the incident laser beam. Peptides and buffers were filtered through a $0.22 \mu \mathrm{m}$ low protein binding filter prior measurements. All presented correlation functions are an average of at least five consecutive measurements of $30 \mathrm{~s}$ each.

UV-vis. UV-vis spectra of samples with encapsulated JR2EC-AuNPs were recorded using a UV-2450 spectrophotometer from Shimadzu (Japan).

Release studies of the oligothiophene p-FTAA. JR2EC $2(50 \mu \mathrm{M}), \mathrm{Zn}^{2+}(4 \mathrm{mM})$ and p-FTAA $(10 \mu \mathrm{M})$ were incubated in $1 \mathrm{ml}$ of Bis-Tris buffer (30 mM, pH 7) for 24 hours. The formed superstructures with encapsulated p-FTAA were thoroughly washed by three rounds of centrifugation $(2,000 \times \mathrm{g}, 30 \mathrm{~s})$ to remove non-encapsulated

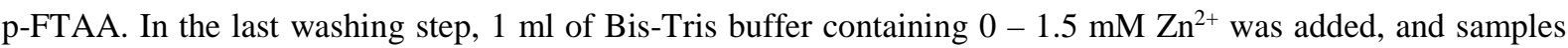
were left to incubate on an orbital-shaker. At each measurement time point, the sample was centrifuged $(2,500 \times$ g, $60 \mathrm{~s}$ ) and $10 \mu \mathrm{l}$ aliquots of the supernatant were sampled. The remaining sample was sequentially vortexed and left for further incubation. After seven days, EDTA was added to the sample to induce complete release of pFTAA. Each sampled $10 \mu \mathrm{l}$ aliquot was diluted 1:100 with EDTA (5 mM) solution to chelate all $\mathrm{Zn}^{2+}$ prior the fluorescence measurement. Fluorescence emission spectra of collected samples were recorded between 430 - 700 nm (excitation $400 \pm 5 \mathrm{~nm}$ ) with an Infinite M1000 Pro plate reader from Tecan (Switzerland). The intensity at $539 \mathrm{~nm}$ for each spectrum was normalized to spectra where $5 \mathrm{mM}$ EDTA had been added to the sample to estimate the cumulative release of p-FTAA. 


\section{Results and discussion}

The 42 amino acid residue helix-loop-helix peptide JR2EC is designed to fold and homodimerize into four-helical bundles at acidic $\mathrm{pH},{ }^{43}$ and at neutral $\mathrm{pH}$ in the presence of $\mathrm{mM}$ concentrations of $\mathrm{Zn}^{2+} .{ }^{44} \mathrm{JR} 2 \mathrm{EC}$ has a Cys residue in the loop region and the linking of two peptide monomers by a disulfide bridge (JR2EC 2 ) results in self-assembly of micrometer long fibers at acidic $\mathrm{pH}$ as a result of peptide folding and a propagating homoassociation when the intra- and intermolecular charge repulsion is reduced upon protonation of Glu residues. ${ }^{43}$ The possibility to control the peptide self-assembly process at physiological $\mathrm{pH}$ using $\mathrm{Zn}^{2+}$ coordination would, however, be very attractive. The oxidation of JR2EC did not affect the $\mathrm{Zn}^{2+}$-induced folding of the peptides at $\mathrm{pH} 7$ (Figure 1b). Furthermore, addition of $\mathrm{Zn}^{2+}(4 \mathrm{mM})$ to a solution of $\mathrm{JR}_{2} \mathrm{EC}_{2}(50 \mu \mathrm{M})$ resulted in a rapid and dramatic increase in turbidity. In contrast to the formation of extended fibers at acidic $\mathrm{pH},{ }^{43}$ addition of $\mathrm{Zn}^{2+}$ at neutral $\mathrm{pH}$ instead induced formation of small spherical particles of about 100 - $200 \mathrm{~nm}$ in radius as seen in scanning electron micrographs (Figure 1c) and which further formed larger fibrous assemblies (Figure 1d). We hypothesise that $\mathrm{Zn}^{2+}$ initiates the folding and homodimerization of the peptides and a propagating self-assembly of short fibers. Due to the excess amount of $\mathrm{Zn}^{2+}$, lateral fiber-fiber interactions causes the fibers to associate into spherical superstructures that, in a diffusion limited aggregation process, form the larger assemblies.

To verify that this hierarchical self-assembly process was the result of specific peptide folding mediated interactions and fiber formation, we synthesized a second peptide where the Cys residue was replaced by a Val (JR2E) and a third peptide with the identical primary sequence as JR2EC but where all L-Ala residues were replaced by its enantiomer D-Ala (D-Ala-JR2EC 2 ). Whereas JR2E cannot be oxidized and hence not assemble into fibers, the D-Ala in D-Ala-JR2EC 2 prevents the peptide from folding into four-helical bundles (Figure 2a, Supporting Figure S1). 

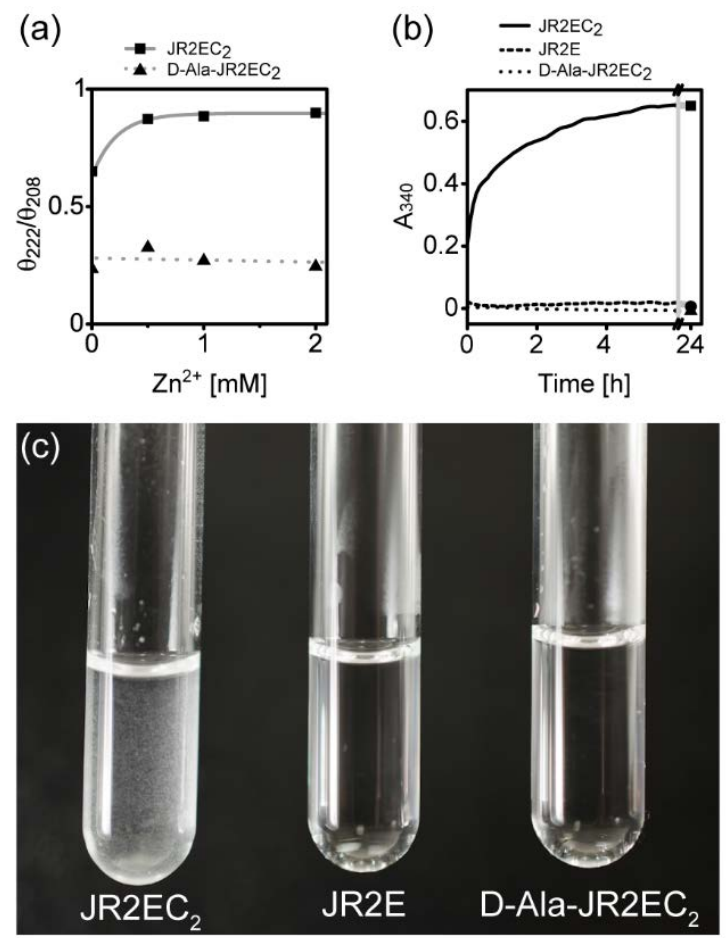

Figure 2 a) The ratio between the CD-signal at 222 and $208 \mathrm{~nm}$ versus $\mathrm{Zn}^{2+}$ concentration for JR2EC ${ }_{2}$ and $\mathrm{D}_{-} \mathrm{Ala}-\mathrm{JR} 2 \mathrm{EC}{ }_{2}$. Lines are drawn as a guide for the eye. b) Absorbance at $340 \mathrm{~nm}$ over 24 hours for JR2EC ${ }_{2}$, JR2E and D-Ala-JR2EC ${ }_{2}$ respectively at pH 7 with $4 \mathrm{mM} \mathrm{Zn}^{2+}$. c)

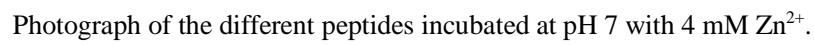

The three peptides were subjected to $\mathrm{Zn}^{2+}$ and the turbidity (absorbance at $340 \mathrm{~nm}, \mathrm{~A}_{340}$ ) was monitored. Only

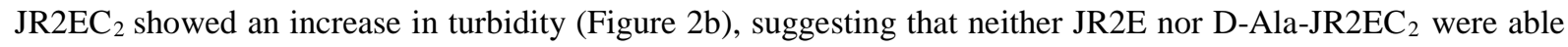
to form assemblies large enough to scatter significant amount of light. The increase in turbidity of JR2EC 2 could clearly be seen by the eye, indicating formation of macroscopic assemblies. Solutions of JR2E and D-Ala-JR2EC 2 remained clear even after more than 30 days of incubation (Figure 2c). Furthermore, dynamic light scattering experiments showed no significant increase in lag times in the autocorrelation functions for neither JR2E nor DAla-JR2EC 2 upon addition of $\mathrm{Zn}^{2+}$ (Supporting Figure S2). In contrast, JR2EC 2 displayed a dramatic decrease in solution dynamics, indicating formation of large assemblies. It is thus evident from these results that the peptides must be capable of folding into four-helical bundles and have the capacity to assemble into fibers to form the superstructures when subjected to $\mathrm{Zn}^{2+}$.

To examine the critical amount of $\mathrm{Zn}^{2+}$ required to induce this hierarchical assembly process, we measured the turbidity over 24 hours after addition of different concentration of $\mathrm{Zn}^{2+}$ to $\mathrm{JR}_{2} \mathrm{EC}_{2}(50 \mu \mathrm{M})$ (Figure 3a). At 0.5 
$m M \mathrm{Zn}^{2+}\left(1: 10\right.$ ratio of JR2EC $\left.2: \mathrm{Zn}^{2+}\right)$ no increase in turbidity could be seen, although JR2EC 2 was almost fully folded at this $\mathrm{Zn}^{2+}$ concentration (Figure 2a). This suggests that lateral fiber-fiber interactions are also needed, in addition to the self-assembly process taking place in the fiber-direction, in order to form the superstructures. At slightly higher concentrations of $\mathrm{Zn}^{2+}(1$ and $1.5 \mathrm{mM})$, an initial increase in turbidity was seen, indicating formation of superstructures. However, these superstructures were not stable and disassembled over time. At $\mathrm{Zn}^{2+}$ concentrations of $2 \mathrm{mM}\left(1: 40\right.$ ratio of JR2EC $\left.2: \mathrm{Zn}^{2+}\right)$ and above, the turbidity increased steadily over time until a maximum was reached, indicating that stable superstructures had been formed. Moreover, the assembly process was rapid as $50 \%$ of the maximum turbidity was reached within 10 min, and $90 \%$ was reached within 1 - 3 hours.

(a)

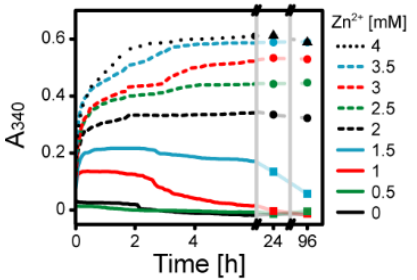

(b)

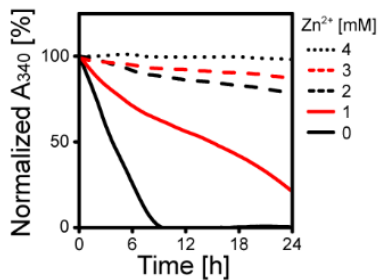

(c)

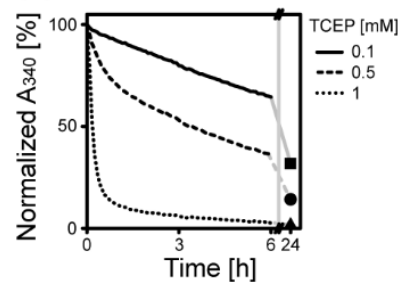

Figure 3 a) Absorbance at $340 \mathrm{~nm}\left(\mathrm{~A}_{340}\right)$ over time with different concentrations of $\mathrm{Zn}^{2+}$. b) Normalized absorbance at $340 \mathrm{~nm}$ after addition of preformed superstructures to buffers with different concentrations of $\mathrm{Zn}^{2+}$. c) Normalized absorbance at $340 \mathrm{~nm}$ after addition of TCEP to preformed superstructures $\left(4 \mathrm{mM} \mathrm{Zn}^{2+}\right)$.

As a critical $\mathrm{Zn}^{2+}$ concentration was needed to form the superstructures, we examined if it was possible to controllable disassemble them after formation by changing the $\mathrm{Zn}^{2+}$ concentration. Decreasing the concentration of $\mathrm{Zn}^{2+}$ in the solution increased the disassembly rate of the superstructures and by varying the $\mathrm{Zn}^{2+}$ concentration this rate could be tuned (Figure $3 \mathrm{~b}$ ). Reducing the $\mathrm{Zn}^{2+}$ concentration in solution to $0 \mathrm{mM}$ led to full disassembly within 12 hours. The disassembly process was fairly linear with time (Supporting Figure S3a) and by plotting the disassembly rate versus the $\mathrm{Zn}^{2+}$ concentration an exponential behavior could be seen (Supporting Figure S3b). Furthermore, we examined the possibility to disassemble the superstructures by addition of EDTA that chelates $\mathrm{Zn}^{2+}$ with high affinity (Log $\left.\mathrm{K}=16.15\right) .{ }^{45}$ The superstructures disassembled almost instantaneously upon addition of EDTA (Supporting Figure S4, Supporting Movie 1). By subsequent addition of $\mathrm{Zn}^{2+}$ it was possible to reassemble the superstructures to some extent, showing the reversibility of the system. By varying the concentration of $\mathrm{Zn}^{2+}$ it is thus possible to control both the assembly and disassembly rate, and as well the reassembly, of the superstructures. 
The disulfide bridge in JR2EC 2 was obviously critical for obtaining the superstructures, and disulfide bridges can be reduced by numerous reducing agents, such as tris(2-carboxyethyl)phospine (TCEP). ${ }^{46}$ To test if it was possible to disassemble the superstructures by reduction of the disulfide bridge in $\mathrm{JR} 2 \mathrm{EC}_{2}$, we added different concentrations of TCEP to preformed superstructures and monitored the change in turbidity over 24 hours. Although TCEP has some minor tendencies to chelate $\mathrm{Zn}^{2+}$, the affinity is significantly lower than for EDTA (Log $\mathrm{K}=2.47) .{ }^{47}$ Furthermore, by keeping the concentration of TCEP low enough in the experiment, the effect on the $\mathrm{Zn}^{2+}$ concentration on the stability of the superstructures will be marginal in comparison to the reduction of the disulfide bridge. By monitoring the turbidity over 24 hours it could clearly be seen that TCEP effectively degraded the superstructures (Figure 3c) indicating that the individual fibers constituting the superstructures were reduced into single four-helical bundles. Furthermore, the TCEP mediated degradation of the superstructures was also rapid and concentration dependent.

Since it was possible to control both the assembly and the disassembly process of the superstructures, we envisioned that it also would be possible to encapsulate different species and to tune their release. As an initial test, gold nanoparticles (40 nm diameter) functionalized with JR2EC (JR2EC-AuNPs) were added to a sample of $\mathrm{JR}_{2} \mathrm{EC}_{2}$ prior addition of $\mathrm{Zn}^{2+}$. The possibility to encapsulate AuNPs in a well-defined peptide material is of great interest in e.g. biosensing applications, enabling e.g. colorimetric monitoring of proteolytic processes ${ }^{48}$ The resulting superstructures had a pink hue, indicating that JR2EC-AuNPs were successfully encapsulated (Figure 4a). ${ }^{49}$ The homogenous encapsulation of JR2EC-AuNPs was further confirmed by transmission electron microscopy (Figure 4b). Addition of EDTA triggered the release of the encapsulated JR2EC-AuNPs, resulting in a blue shift (19 nm) of the localized surface plasmon (LSPR) band as the particles were resuspended (Figure 4c). 

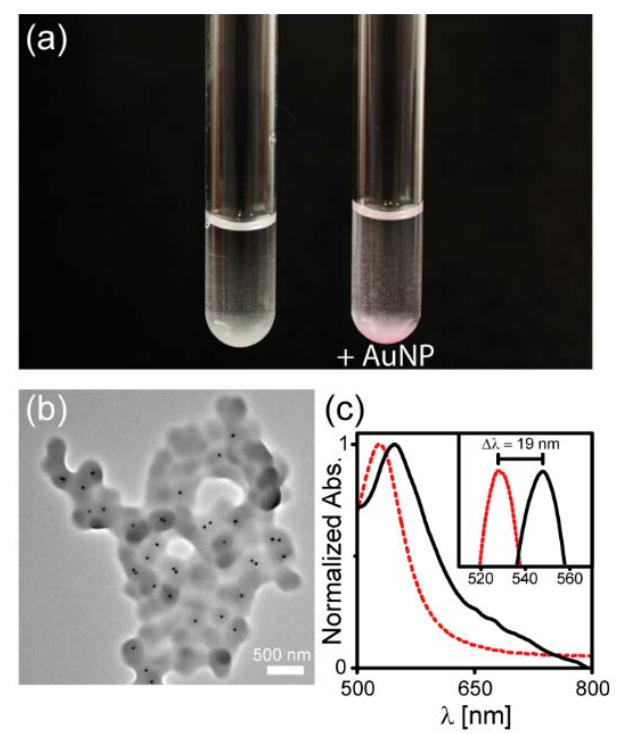

Figure 4 a) Photograph of superstructures with encapsulated JR2EC-AuNP. b) TEM micrograph of superstructures with encapsulated JR2ECAuNP. c) Normalized absorbance spectra of encapsulated JR2EC-AuNP (black, solid) and released JR2EC-AuNP by chelation of Zn ${ }^{2+}$ by EDTA (red, dashed). The blue shift of $19 \mathrm{~nm}$ of the LSPR band is likely a consequence of the decrease in refractive index and reduction in plasmonic coupling between adjacent nanoparticles when the particles were released. ${ }^{50}$

To investigate the possibility to also encapsulate molecular compounds, two different fluorescent molecules, rhodamine-B (RhoB) and the thiophene-based conjugated oligomer p-FTAA (Figure S5), ${ }^{39}$ were added prior addition of $\mathrm{Zn}^{2+}$. Both compounds contain carboxyl groups that can interact with $\mathrm{Zn}^{2+}$. Whereas $\mathrm{RhoB}$ was used as a model system, p-FTAA has recently been shown to significantly reduce the toxicity of prions and amyloid- $\beta$ peptides and finding means to improve the pharmacokinetics by controlled release is thus of great interest. ${ }^{51-53}$ Both RhoB and p-FTAA were encapsulated in the superstructures (Figure 5a-b, Supporting Figure S6) and could be released by addition of EDTA (Supporting Figure S7, Supporting Movie 2). The encapsulation efficiency of RhoB was significantly lower as compared to p-FTAA ( $0.4 \%$ compared to $75 \%$, see Supporting Table S1), which is likely due to the lower amount of carboxyl groups in RhoB as compared to p-FTAA. In addition, p-FTAA is designed to effectively bind to divalent metal ion containing fibrous structures such as amyloid plaques. ${ }^{54}$ Due to the low encapsulation efficiency of RhoB, only p-FTAA was used for further release studies.

To further investigate the possibility to control the release rate of encapsulated compounds over an extended period of time, we dispersed p-FTAA loaded superstructures in solutions with different concentrations of $\mathrm{Zn}^{2+}(0-1.5$ $\mathrm{mM}$ ) and studied the cumulative release over seven days (Figure 5c). Without $\mathrm{Zn}^{2+}$ in the solution roughly $50 \%$ of the p-FTAA had been released within 30 min and more than $90 \%$ had been released within 24 hours. However, 


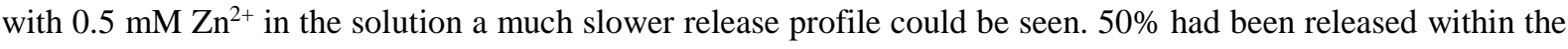
first 6 hours, but only 70\% of the p-FTAA had been released after seven days. Superstructures dispersed in $1 \mathrm{mM}$ $\mathrm{Zn}^{2+}$ had an even slower release profile, with roughly 30\% p-FTTA release after 7 days, whereas superstructures dispersed in $1.5 \mathrm{mM} \mathrm{Zn}^{2+}$ showed no significant release of p-FTAA within the measured time span.
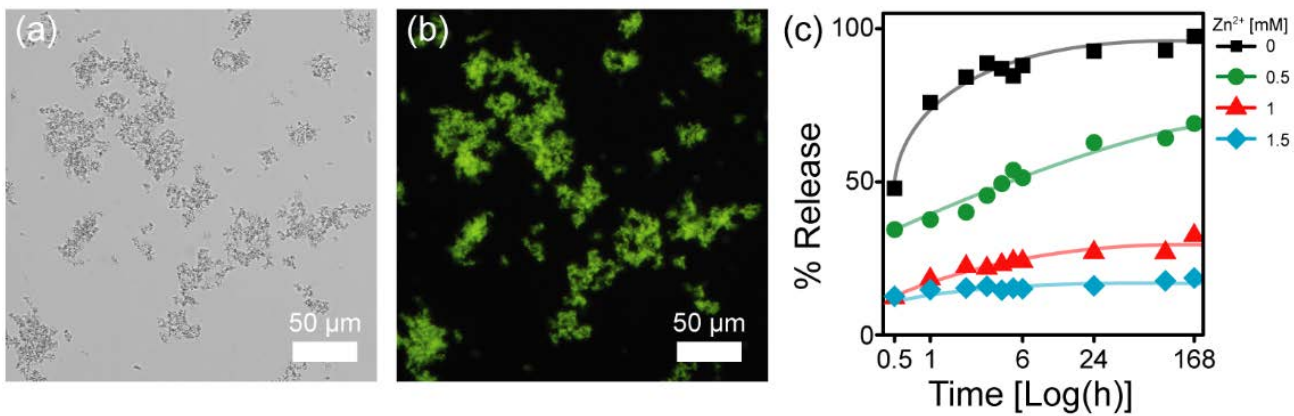

Figure 5 a) Light micrograph and b) Epi-Fluorescence micrograph of superstructures containing p-FTAA. c) Release of p-FTAA from superstructures over seven days. Lines are drawn as a guide for the eye.

\section{Conclusions}

In conclusion, we have shown that a $\mathrm{Zn}^{2+}$ triggered propagating folding-mediated association of the non-linear peptide $\mathrm{JR}_{2} \mathrm{EC}_{2}$ results in formation of sub-micron sized fibrous assemblies comprised of spherical superstructures. The resulting superstructures can be reversibly assembled and disassembled by adjusting the concentration of $\mathrm{Zn}^{2+}$ or by reducing the disulfide bridge in $\mathrm{JR}_{2} \mathrm{EC}_{2}$. Both nanoparticles and drugs could be efficiently encapsulated in the superstructures and the release rate could be modulated by the $\mathrm{Zn}^{2+}$ concentration. The possibility to tune both the peptide self-assembly process and the release of compounds by means of different stimuli make this system an attractive candidate in both drug delivery and bioanalytical applications. 


\section{Associated content}

\section{Supporting Information.}

The Supporting Information is available free of charge on the ACS Publications website at DOI: XXXXXXXXX Additional characterization data (PDF).

Supporting Movie 1.

Supporting Movie 2.

\section{Author information}

\section{Corresponding Author}

* E-mail: daniel.aili@liu.se

\section{Author Contributions}

† These authors contributed equally to this work

\section{Notes}

The authors declare no competing financial interest.

\section{Acknowledgment}

This work was supported by the Swedish Research Council (621-2011-4319), the Swedish Foundation for Strategic Research (ICA10-0002), Linköping University and the Swedish Government Strategic Research Area in Materials Science on Functional Materials at Linköping University (Faculty Grant SFO-Mat-LiU No 2009 00971 ). During this study C.A. was enrolled in the graduate school Forum Scientium. We thanks Dr. Peter Nilsson and Dr. Leif Johansson for providing us with p-FTAA. 


\section{References}

(1) Fan, Z.; Sun, L.; Huang, Y.; Wang, Y.; Zhang, M., Bioinspired Fluorescent Dipeptide Nanoparticles for Targeted Cancer Cell Imaging and Real-Time Monitoring of Drug Release. Nat. Nanotechnol. 2016, 11 (4), 388-394.

(2) Bawa, R.; Fung, S.-Y.; Shiozaki, A.; Yang, H.; Zheng, G.; Keshavjee, S.; Liu, M., Self-Assembling Peptide-Based Nanoparticles Enhance Cellular Delivery of the Hydrophobic Anticancer Drug Ellipticine through Caveolae-Dependent Endocytosis. Nanomedicine 2012, 8 (5), 647-654.

(3) Sigg, S. J.; Postupalenko, V.; Duskey, J. T.; Palivan, C. G.; Meier, W., Stimuli-Responsive Codelivery of Oligonucleotides and Drugs by Self-Assembled Peptide Nanoparticles. Biomacromolecules 2016, 17 (3), 935-945.

(4) Gribbon, C.; Channon, K. J.; Zhang, W.; Banwell, E. F.; Bromley, E. H. C.; Chaudhuri, J. B.; Oreffo, R. O. C.; Woolfson, D. N., Magicwand: A Single, Designed Peptide That Assembles to Stable, Ordered A-Helical Fibers. Biochemistry 2008, 47 (39), 10365-10371. (5) Morgan, C. E.; Dombrowski, A. W.; Rubert Pérez, C. M.; Bahnson, E. S. M.; Tsihlis, N. D.; Jiang, W.; Jiang, Q.; Vercammen, J. M.; Prakash, V. S.; Pritts, T. A.; Stupp, S. I.; Kibbe, M. R., Tissue-Factor Targeted Peptide Amphiphile Nanofibers as an Injectable Therapy to Control Hemorrhage. ACS Nano 2016, 10 (1), 899-909.

(6) Pandya, M. J.; Spooner, G. M.; Sunde, M.; Thorpe, J. R.; Rodger, A.; Woolfson, D. N., Sticky-End Assembly of a Designed Peptide Fiber Provides Insight into Protein Fibrillogenesis. Biochemistry 2000, 39 (30), 8728-8734.

(7) Bakota, E. L.; Sensoy, O.; Ozgur, B.; Sayar, M.; Hartgerink, J. D., Self-Assembling Multidomain Peptide Fibers with Aromatic Cores. Biomacromolecules 2013, 14 (5), 1370-1378.

(8) Martin, C.; Oyen, E.; Mangelschots, J.; Bibian, M.; Ben Haddou, T.; Andrade, J.; Gardiner, J.; Van Mele, B.; Madder, A.; Hoogenboom, R.; Spetea, M.; Ballet, S., Injectable Peptide Hydrogels for Controlled-Release of Opioids. Med. Chem. Commun. 2016, 7 (3), $542-549$.

(9) Motamed, S.; Del Borgo, M. P.; Kulkarni, K.; Habila, N.; Zhou, K.; Perlmutter, P.; Forsythe, J. S.; Aguilar, M. I., A Self-Assembling $\beta$ Peptide Hydrogel for Neural Tissue Engineering. Soft Matter 2016, 12 (8), 2243-2246.

(10) Fleming, S.; Debnath, S.; Frederix, P. W. J. M.; Hunt, N. T.; Ulijn, R. V., Insights into the Coassembly of Hydrogelators and Surfactants Based on Aromatic Peptide Amphiphiles. Biomacromolecules 2014, 15 (4), 1171-1184.

(11) Smith, D. J.; Brat, G. A.; Medina, S. H.; Tong, D.; Huang, Y.; Grahammer, J.; Furtmüller, G. J.; Oh, B. C.; Nagy-Smith, K. J.; Walczak, P.; Brandacher, G.; Schneider, J. P., A Multiphase Transitioning Peptide Hydrogel for Suturing Ultrasmall Vessels. Nat. Nanotechnol. 2016, 11 (1), 95-102.

(12) Woolfson, D. N., The Design of Coiled-Coil Structures and Assemblies. Adv. Protein Chem. 2005, 70, 79-112.

(13) Schense, J. C.; Bloch, J.; Aebischer, P.; Hubbell, J. A., Enzymatic Incorporation of Bioactive Peptides into Fibrin Matrices Enhances Neurite Extension. Nat. Biotech. 2000, 18 (4), 415-419.

(14) Ghosh, A.; Haverick, M.; Stump, K.; Yang, X.; Tweedle, M. F.; Goldberger, J. E., Fine-Tuning the Ph Trigger of Self-Assembly. J. Am. Chem. Soc. 2012, 134 (8), 3647-3650.

(15) Baio, J. E.; Schach, D.; Fuchs, A. V.; Schmuser, L.; Billecke, N.; Bubeck, C.; Landfester, K.; Bonn, M.; Bruns, M.; Weiss, C. K.; Weidner, T., Reversible Activation of Ph-Sensitive Cell Penetrating Peptides Attached to Gold Surfaces. Chem. Commun. 2015, 51 (2), 273275.

(16) Rajagopal, K.; Lamm, M. S.; Haines-Butterick, L. A.; Pochan, D. J.; Schneider, J. P., Tuning the pH Responsiveness of $\beta$-Hairpin Peptide Folding, Self-Assembly, and Hydrogel Material Formation. Biomacromolecules 2009, 10 (9), 2619-2625. 
(17) Navon, Y.; Zhou, M.; Matson, J. B.; Bitton, R., Dendritic Elastin-Like Peptides: The Effect of Branching on Thermoresponsiveness. Biomacromolecules 2016, 17 (1), 262-270.

(18) Huang, R.; Wang, Y.; Qi, W.; Su, R.; He, Z., Temperature-Induced Reversible Self-Assembly of Diphenylalanine Peptide and the Structural Transition from Organogel to Crystalline Nanowires. Nanoscale Res. Lett. 2014, 9 (1), 1-9.

(19) Sawada, T.; Matsumoto, A.; Fujita, M., Coordination-Driven Folding and Assembly of a Short Peptide into a Protein-Like TwoNanometer-Sized Channel. Angew. Chem. Int. Ed. 2014, 53 (28), 7228-7232.

(20) Aili, D.; Enander, K.; Rydberg, J.; Nesterenko, I.; Björefors, F.; Baltzer, L.; Liedberg, B., Folding Induced Assembly of Polypeptide Decorated Gold Nanoparticles. J. Am. Chem. Soc. 2008, 130 (17), 5780-5788.

(21) Hsu, W.; Chen, Y.-L.; Horng, J.-C., Promoting Self-Assembly of Collagen-Related Peptides into Various Higher-Order Structures by Metal-Histidine Coordination. Langmuir 2012, 28 (6), 3194-3199.

(22) Aronsson, C.; Dånmark, S.; Zhou, F.; Öberg, P.; Enander, K.; Su, H.; Aili, D., Self-Sorting Heterodimeric Coiled Coil Peptides with Defined and Tuneable Self-Assembly Properties. Sci. Rep. 2015, 5, 14063.

(23) Thomas, F.; Boyle, A. L.; Burton, A. J.; Woolfson, D. N., A Set of De Novo Designed Parallel Heterodimeric Coiled Coils with Quantified Dissociation Constants in the Micromolar to Sub-Nanomolar Regime. J. Am. Chem. Soc. 2013, 135 (13), $5161-5166$.

(24) Zheng, T.; Bulacu, M.; Daudey, G.; Versluis, F.; Voskuhl, J.; Martelli, G.; Raap, J.; Sevink, G. J. A.; Kros, A.; Boyle, A. L., A NonZipper-Like Tetrameric Coiled Coil Promotes Membrane Fusion. RSC Adv. 2016, 6 (10), 7990-7998.

(25) Xu, X.-D.; Lin, B.-B.; Feng, J.; Wang, Y.; Cheng, S.-X.; Zhang, X.-Z.; Zhuo, R.-X., Biological Glucose Metabolism Regulated Peptide Self-Assembly as a Simple Visual Biosensor for Glucose Detection. Macromol. Rapid Commun. 2012, 33 (5), $426-431$.

(26) Selegard, R.; Enander, K.; Aili, D., Generic Phosphatase Activity Detection Using Zinc Mediated Aggregation Modulation of Polypeptide-Modified Gold Nanoparticles. Nanoscale 2014, 6 (23), 14204-14212.

(27) Wang, Q.; Zhang, X.; Zheng, J.; Liu, D., Self-Assembled Peptide Nanotubes as Potential Nanocarriers for Drug Delivery. RSC Adv. 2014, 4 (48), 25461-25469

(28) Yan, X.; Zhu, P.; Fei, J.; Li, J., Self-Assembly of Peptide-Inorganic Hybrid Spheres for Adaptive Encapsulation of Guests. Adv. Mater. 2010, 22 (11), 1283-1287.

(29) Galler, K. M.; Hartgerink, J. D.; Cavender, A. C.; Schmalz, G.; D'Souza, R. N., A Customized Self-Assembling Peptide Hydrogel for Dental Pulp Tissue Engineering. Tissue Eng. Part A 2011, 18 (1-2), 176-184.

(30) Ellis-Behnke, R. G.; Liang, Y.-X.; You, S.-W.; Tay, D. K. C.; Zhang, S.; So, K.-F.; Schneider, G. E., Nano Neuro Knitting: Peptide Nanofiber Scaffold for Brain Repair and Axon Regeneration with Functional Return of Vision. Proc. Natl. Acad. Sci. USA 2006, 103 (13), 5054-5059.

(31) Fantner, G. E.; Hassenkam, T.; Kindt, J. H.; Weaver, J. C.; Birkedal, H.; Pechenik, L.; Cutroni, J. A.; Cidade, G. A. G.; Stucky, G. D.; Morse, D. E.; Hansma, P. K., Sacrificial Bonds and Hidden Length Dissipate Energy as Mineralized Fibrils Separate During Bone Fracture. Nat. Mater. 2005, 4 (8), 612-616

(32) Mak, W. C.; Selegård, R.; Garbrecht, M.; Aili, D., Probing Zinc-Protein-Chelant Interactions Using Gold Nanoparticles Functionalized with Zinc-Responsive Polypeptides. Part. Part. Syst. Char. 2014, 31 (11), 1127-1133.

(33) Krishna, S. S.; Majumdar, I.; Grishin, N. V., Structural Classification of Zinc Fingers: Survey and Summary. Nucleic Acids Res. 2003, $31(2), 532-550$.

(34) Lindskog, S., Structure and Mechanism of Carbonic Anhydrase. Pharmacol. Ther. 1997, 74 (1), 1-20. 
(35) Trzaskowski, B.; Adamowicz, L.; Deymier, P. A., A Theoretical Study of Zinc(Ii) Interactions with Amino Acid Models and Peptide Fragments. J. Biol. Inorg. Chem. 2008, 13 (1), 133-137.

(36) Fazary, A. E.; Ramadan, A. M., Stability Constants and Complex Formation Equilibria between Iron, Calcium, and Zinc Metal Ions with Vitamin B9 and Glycine. Complex Met. 2014, 1 (1), 139-148.

(37) Singla, A. K.; Wadhwa, H., Zinc-Aspirin Complex: Synthesis, Physicochemical and Biological Evaluation. Int. J. Pharm. 1994, 108 (3), 173-185.

(38) Sigel, H.; Griesser, R., Nucleoside 5[Prime or Minute]-Triphosphates: Self-Association, Acid-Base, and Metal Ion-Binding Properties in Solution. Chem. Soc. Rev. 2005, 34 (10), 875-900.

(39) Aslund, A.; Sigurdson, C. J.; Klingstedt, T.; Grathwohl, S.; Bolmont, T.; Dickstein, D. L.; Glimsdal, E.; Prokop, S.; Lindgren, M.; Konradsson, P.; Holtzman, D. M.; Hof, P. R.; Heppner, F. L.; Gandy, S.; Jucker, M.; Aguzzi, A.; Hammarstrom, P.; Nilsson, K. P., Novel Pentameric Thiophene Derivatives for in Vitro and in Vivo Optical Imaging of a Plethora of Protein Aggregates in Cerebral Amyloidoses. ACS Chem. Biol. 2009, 4 (8), 673-84.

(40) Ellman, G. L., Tissue Sulfhydryl Groups. Arch. Biochem. Biophys. 1959, 82 (1), 70-77.

(41) Liu, X.; Atwater, M.; Wang, J.; Huo, Q., Extinction Coefficient of Gold Nanoparticles with Different Sizes and Different Capping Ligands. Colloids Surf., B 2007, 58 (1), 3-7.

(42) Lau, S. Y.; Taneja, A. K.; Hodges, R. S., Synthesis of a Model Protein of Defined Secondary and Quaternary Structure. Effect of Chain Length on the Stabilization and Formation of Two-Stranded Alpha-Helical Coiled-Coils. J. Biol. Chem. 1984, 259 (21), $13253-61$.

(43) Aili, D.; Tai, F. I.; Enander, K.; Baltzer, L.; Liedberg, B., Self-Assembly of Fibers and Nanorings from Disulfide-Linked Helix-LoopHelix Polypeptides. Angew. Chem. Int. Ed. 2008, 47 (30), 5554-6.

(44) Aili, D.; Enander, K.; Rydberg, J.; Lundström, I.; Baltzer, L.; Liedberg, B., Aggregation-Induced Folding of a De Novo Designed Polypeptide Immobilized on Gold Nanoparticles. J. Am. Chem. Soc. 2006, 128 (7), 2194-2195.

(45) Irving, H.; Williams, R. J. P., 637. The Stability of Transition-Metal Complexes. J. Chem. Soc. 1953, (0), 3192-3210.

(46) Getz, E. B.; Xiao, M.; Chakrabarty, T.; Cooke, R.; Selvin, P. R., A Comparison between the Sulfhydryl Reductants Tris(2Carboxyethyl)Phosphine and Dithiothreitol for Use in Protein Biochemistry. Anal. Biochem. 1999, 273 (1), $73-80$.

(47) Krężel, A.; Latajka, R.; Bujacz, G. D.; Bal, W., Coordination Properties of Tris(2-Carboxyethyl)Phosphine, a Newly Introduced Thiol Reductant, and Its Oxide. Inorg. Chem. 2003, 42 (6), 1994-2003.

(48) Hume, J.; Chen, R.; Jacquet, R.; Yang, M.; Montclare, J. K., Tunable Conformation-Dependent Engineered Protein· Gold Nanoparticle Nanocomposites. Biomacromolecules 2015, 16 (6), 1706-1713.

(49) Su, K. H.; Wei, Q. H.; Zhang, X.; Mock, J. J.; Smith, D. R.; Schultz, S., Interparticle Coupling Effects on Plasmon Resonances of Nanogold Particles. Nano Lett. 2003, 3 (8), 1087-1090.

(50) Willets, K. A.; Van Duyne, R. P., Localized Surface Plasmon Resonance Spectroscopy and Sensing. Annu. Rev. Phys. Chem. 2007, 58, 267-97.

(51) Civitelli, L.; Sandin, L.; Nelson, E.; Khattak, S. I.; Brorsson, A. C.; Kagedal, K., The Luminescent Oligothiophene P-Ftaa Converts Toxic Abeta1-42 Species into Nontoxic Amyloid Fibers with Altered Properties. J. Biol. Chem. 2016, 291 (17), $9233-43$.

(52) Herrmann, U. S.; Schütz, A. K.; Shirani, H.; Huang, D.; Saban, D.; Nuvolone, M.; Li, B.; Ballmer, B.; Åslund, A. K. O.; Mason, J. J.; Rushing, E.; Budka, H.; Nyström, S.; Hammarström, P.; Böckmann, A.; Caflisch, A.; Meier, B. H.; Nilsson, K. P. R.; Hornemann, S.; Aguzzi, A., Structure-Based Drug Design Identifies Polythiophenes as Antiprion Compounds. Sci. Transl. Med. 2015,7 (299), 299 ra123. 
(53) Margalith, I.; Suter, C.; Ballmer, B.; Schwarz, P.; Tiberi, C.; Sonati, T.; Falsig, J.; Nystrom, S.; Hammarstrom, P.; Aslund, A.; Nilsson, K. P.; Yam, A.; Whitters, E.; Hornemann, S.; Aguzzi, A., Polythiophenes Inhibit Prion Propagation by Stabilizing Prion Protein (Prp) Aggregates. J. Biol. Chem. 2012, 287 (23), 18872-87.

(54) Kepp, K. P., Bioinorganic Chemistry of Alzheimer’s Disease. Chem. Rev. 2012, 112 (10), 5193-5239. 